\title{
On Translation of Cultural Images in Ancient Chinese Poems
}

\author{
Hongwei Ye \\ School of Foreign Languages, Shanghai University of Engineering Science, Shanghai, China
}

\begin{abstract}
The cultural difference between China and the West is huge, which will have an important impact on Chinese-English translation. As an important part of Chinese literature, ancient Chinese poetry contains a lot of cultural images which will bring great challenges to translators. This paper aims to analyze the strategies of translating cultural images in ancient Chinese poems.
\end{abstract}

Index Terms - translation, cultural images, ancient Chinese poems

\section{INTRODUCTION}

China is known as a nation of poetry, especially the ancient Chinese poetry of the Tang and Song dynasty, which marks the peak of Chinese poetry. It occupies an important position not only in the history of Chinese poetry but also in Chinese literature. A splendid cultural heritage is a precious treasure for the whole world; therefore the translation of ancient Chinese poetry plays an important role in the spread of Chinese literature to other nations because it is an indispensable link for foreigners to get a deeper understanding of Chinese culture and literature.

\section{The Translation of Cultural Images in AnCient Chinese Poems}

The thinking methods of different nationalities have unique characteristics, which are prominently reflected languages and cultures. It is these characteristics, that is, differences, that constitute a barrier to translation (Shui Xiaozhong, 1998). Ancient poetry is an extremely golden treasure with abundant cultural elements, which is the reflection of traditional Chinese culture and deserves the appreciation of all human beings. The cultural elements include all the culturally loaded words or expressions that are particular to Chinese culture.

\section{A. Allusions}

Allusion is a commonly used device in composing poems. Though brief in form, allusions contain a lot of information, and are really effective and vivid in expressing profound emotion or ideas, so poets frequently use them. Reading ancient Chinese poems, one may come across allusions now and then. Some of the allusions are too familiar and well known to be recognized by readers before their meanings are got across, while others may only be understood with the help of notes or reference books. The employment of allusions, on the one hand, makes the poem concise and comprehensive: a short phrase of two or three characters can convey the essence of a legend or an old fable to the readers. On the other hand, the employment of allusion is in conformity with the conservative ideas and traditional psychology of the Chinese. Some allusions are really difficult to understand even for the native readers.

Poets, especially those who are in unfavorable social environment, tend to hide their ambitions, their complaints and their hatred in allusions. By using an allusion, the poet can endow the present situation with additional implications and associations. An allusion is an economical way of presenting a situation or a subtitle for narration and description. Ancient Chinese poems teem with allusions and poets frequently resort to allusions, which come from their own historical and cultural background, so the allusions deserve our special attention. For example:

Original:

日暮东风怨啼鸟，落花犹似坠楼人。(杜牧《金谷园》)

Version 1:

Dusk comes, the east wind blows, and birds

Pipe forth a mournful sound;

Petals, like nymphs from balconies,

Comes tumbling to the ground.

(Tr. Giles.)

Version 2:

The bird in the east wind

Wails its sad heart at he evening hour,

And the blossoms fall from the trees

Like unlucky women falling from the tower.

(Tr. Luo Zhiye) 
This poem was written when the poet visited the Golden Valley Garden in spring. In the original poem, “坠楼人” is an allusion, referring to Lu Zhu(绿珠), a concubine of Shi Chong(石崇) who was a merchant in the late Jin Dynasty. After the decline of Shi's family, another man wanted to get $\mathrm{Lu} \mathrm{Zhu,} \mathrm{who} \mathrm{was} \mathrm{faithful} \mathrm{to} \mathrm{Shi} \mathrm{and} \mathrm{jumped} \mathrm{from} \mathrm{the}$ building. By using this allusion, the poet compares the falling flower to Green Pearl, because they are somewhat similar to each other. However the translations of this important cultural element are not so satisfying. In Version 1, "nymphs" refer to the minor goddess represented as beautiful maidens inhabiting trees, waters and mountains in Greek mythology. This is a typical example of domesticating translation. Though it is easier for target language readers to understand, the original cultural flavor is lost. In version 2, translator use "unlucky women" to translator this allusion. It is only a kind of explanation with the cultural image totally lost.

\section{B. Similes and Metaphors}

Similes and metaphors are perhaps the commonest figures of speech in language. When people describe something, they like to make comparisons. A simile is a direct comparison between two or more unlike things, normally "like" or "as" is used to transfer the quality we associate with the other. Sometimes the association is between unfamiliar things and familiar ones, between old experiences and new ones, or between abstract ideas and concrete images. A metaphor is an implied comparison between two or more unlike things.

In most cases, culturally loaded words are peculiar to a particular nation. They are the result of the particular living environment, customs and tradition, national spirit etc. of that nation. Because of the different social and cultural backgrounds and different ways of thinking, which is reflected by analogy making, the metaphors in one language are not always identical in another. Poetry, not only the carrier of ideology and emotion, but also carrier of culture, reflects the characteristics of the national culture which may be the barriers to the TL readers' understanding.

In ancient Chinese poems, an extremely outstanding characteristic is the abundant use of metaphors. The metaphorical objects, ideas, and events remind us of other parts of our experience. The mental associations help us to understand the meanings of the poetry vividly. Generally speaking, the metaphorical image of ancient Chinese poems ought to be translated into English by a metaphorical image. The use of general and abstract words to translate metaphors (domesticating translation) is the least favorable strategy the translator may employ. Look at the following examples:

Original:

谁言寸草心, 报得三春辉。(孟郊《游子吟》)

Version 1:

Such life-long mother's love how may

One simple little heart repay?

(Tr. W.J.B Fletcher)

Version 2:

But how much love has he inch-long grass

For three spring months of the light of the sun?

(Tr. Wu Juntao)

The phrase “寸草心” is a metaphor for the child's heart and the phrase “三春晖” is a metaphor for the mother's love and nurture. By using these metaphors, the poet expresses his deep gratitude for his mother's love and regret for not being able to repay all the love. In version 1, the original cultural images are invisible and the meanings of the two images are explicated. It is inconsistent with the poet's intention to convey the meaning through these metaphorical images. The implications are spelled out without giving readers any space of imagination. In version 2 , the original images are faithfully translated. This foreignized translation does not cause any misunderstanding. It requires the readers to comprehend the images in the textual context and arrive at the implications. Sometimes it is necessary to capture the true implied meaning through the literal meaning of words.

When metaphors, similes and other figures of speech are skillfully used in the line, the true meaning of the poem may not be easily available. If translated literally, Western readers will find it inexplicable or ridiculous (Gao Jiazheng, 1999).

\section{Proper Names}

Proper names refer to persons, living creatures, places, objects or processes that are particular to a single cultural community. The frequent use of proper names is also one of the characteristics of ancient Chinese poetry. Since ancient Chinee poetry is a highly concentrated and condensed literary form, proper names in it are often imbued with rich cultural connotation. Because these proper nouns are used repeatedly in poetry creation, they have become so culturally loaded and the mention of them can spontaneously arouse certain feeling in Chinese.

In the translation of proper names some translators like using words seeming to be a TL proper name to translate a SL proper name for the purpose of increasing readability. But this treatment may block cultural exchanges and give readers an impression that SL culture and TL culture are just the same in the way of naming animals, persons, places, etc. In practice, the translator must keep in mind that every proper name has its own cultural background. If the cultural background is significant for the understanding of poems, it should be expressed in the TL text. Specifically speaking, 
in the translation of proper names, the translator should also try his best to transfer as many cultural messages of proper manes as possible to the TL reader. For example:

Original:

暖风熏得游人醉, 直把杭州作汴州。(林升《题林安邸》)

Version 1:

People are so intoxicated by the present warm breeze,

Surely, they are taking Hangzhou to be Bianzhou .

(Tr. Wenshu)

Version 2;

The wind is so warm and gentle

It lulls the tourists into dreams.

They forget the old capital

They think hangzhou is bianzhou.

(Tr. Wang Shouyi)

Here”杭州” and “泣州” are not just two common place names, but place names with a strong cultural and historical color. “泣州”refers to the capital city of the Northern Song Dynasty, which had already been conquered by the Jin Dynasty when the poet wrote this poem. The rulers of the Northern Song wanted to regain the lost capital but did not make any efforts and indulged in delight of pleasure in the new capital Lin'an, which was Hangzhou. The last line has the satirical meaning that if the rulers did not stop seeking pleasure; the invaders would also take Hangzhou. In both versions, the two places names are reserved through foreignizing translation-transliteration.

Original:

劝君更尽一杯酒, 西出阳关无故人。(王维《送元二使安西》)

Version 1:

Won't you help yourself to more wine?

West of Sun Pass friends won't be see.

(Tr. Zhao zhentao)

Version2:

I urge you to empty another cup of wine,

West of the Yangguan Pass you'll see no more of mine.

(Tr. Guo Zhuzhang)

Version 3:

Drink up one more cup of wine, sire,

West of the Yangguan Pass * you can hardly find an old friend.

* The pass here refers to the south of Yumen Pass, one of the frontier passes to the West regions. It is in present-day Gansu Province.

(Tr. Huang Xinqu)

Located 70 kilometers southwest of Dunhuang City, Gansu Province, Yangguan(阳关), founded in the Western Han Emperor period. It relies on water as a pass and faces Yumenguan(玉门关) across the water. It was not only the most important pass for the Han Dynasty to defend the northwest nomadic invasion, but also an important gateway on the Silk Road Central Plains to the western region, central Asia and other places. This farewell song writen by Wang Wei makes Yangguan famous all over the world and has been considered a masterpiece through ages. Nowadays, Yangguan scenic spot together with other cultural relics, is one of the most densest places of Dunhuang cultural relics distribution. Most of the tourists at home and abroad started to understand Yang Guan from the poem of Wang Wei.In Version 1, “阳 关” is directly translated into “Sun Pass", It did not translate the real cultural connotation of the name of “阳关”.“阳 关" is the gateway to the western region. However, Sun Pass does not give this kind of association. Inversion 2, the translator transliterated Yangguan, retaining the original name of the place, which is a good choice from the perspective of tourism promotion, but may not be familiar to the general foreigners. Comparatively speaking, Version 3 makes up for this defect by translating "阳关" directly into Yanguan Pass and then compensating with annotations, which not only helps readers better understand not only the connotation of Yangguan, but also the meaning of the whole poem.

\section{Folk Customs}

Custom refers to an established and habitual practice, especially of a social kind, that is typical of a particular group of people. So various peoples with different history, living surroundings etc. hold different customs. The culture of Chinese folk customs originates from the cultural exploration and transmission of millions of Chinese people. Its diversity and richness survive through ages of changes and the development of history. It is the boiled-down gem and crystallization, which brighten so much the long-standing and well-established traditional Chinese culture. Being an important part of it, the culture of folk customs is, to a certain extent, an insight of the ancient civilization of the Chinese nation, which has made its major contributions to the development of the civilization of the world.

There are many words related to customs in ancient Chinese poetry. They are still the most primitive and vital 
traditions in Chinese culture, with a long history, diverse forms and rich contents. Chinese culture-loaded words have a long history. A translator's better understanding of cultural factors in this field will contribute to effective translation.

Original:

清明时节雨纷纷, 路上行人欲断魂。(杜牧《清明》)

Version 1:

It drizzles and drizzles on All Souls festival day,

I feel heavy at heart, a wayfarer on my journey.

(Tr. Cai Tinggan)

Version 2:

It drizzles thick on the Pure Brightness Day.

I travel with my heart lost in dismay.

(Tr. Wu Juntao)

Qingming(清明), meaning clear and bright, is the day for mourning the dead. It has been a folk festival in China from time immemorial. This is the most important sacrificial day. At this time, both Han and minority ethnic groups offered sacrifices to their ancestors and wept for the graves of the deceased. Qingming Festival is a festival of mixed joy and sorrow. This day is not only a day for people to visit the cemetery to mourn the lost ancestors, but also a day when nature wakes up and people go out to celebrate the coming of spring. Compared with the sadness of grave sweepers, people also enjoy the hope of spring on this day. Qingming Festival is a sunny, shady day, and nature is once again active. Since ancient times, people have followed the custom of spring outing.

In this poem, the poet gave a description of anxiety of the pedestrians who are still on the way back home. The cultural connation of this festival is the soul of the poem. In the first version, this Chinese traditional festival is domesticated into All Souls festival, which may give the readers misconception that Chinese also celebrate this Western festival. From the perspective of cultural exchange, version 2, translating the festival literarily, is more successful.

\section{E. Culture-specific Words and Expressions}

Indeed, different peoples live in a similar physical environment on the same planet, and every language contains expressions that describe the physical world-books, tables, rice, water, mothers, and so on. But through a long and unique evolution, each culture has developed a different view of the world. In addition to the common core expressions, most of them are conceptual or out-of-scope, each language has millions of culture-specific expressions, all of which are richly related to the nation. Therefore, the same object can be conceptualized or symbolized with different cultural colors or flavors.

For example, the words like, fire, sea, Roland, castle, sport, shepherd, nightingale, evoke different associations in the minds of British and Chinese people. To British people, these words are imbued with imaginations. Similarly, the words like, wind, moon, river, lake, plum, chrysanthemum, sparrow, stele, flute, monk, reclusion, li(礼), yingyang（阴阳） etc also evoke associations and sentiments in the minds of Chinese people that western people may not understand. (Zhu Guangqian, 1984) Look at the following examples:

Original:

不向东山久, 蓄薇几度花?

白云还自散, 明月落谁家? (李白《忆东山》)

Version:

To Tung Shan Cave so long I have not been!

How often have its roses filled with bloom!

Its silver clouds all pass away unseen.

Descends Dianna there? To visit whom?

(Tr. Fletcher)

Chinese poetry “月” is an important cultural image. There are many more poems or literary works taking the Moon as the subject matter.: “海上生明月, 天涯共此时。” (The moon is borne so bright above the sea/ And bathes at once the distant one and me. Tr. Ni Peiling); “举杯邀明月, 对影成三人” (I raise my cup to invite the Moon who blends/ Her light with my Shadow and we're three friends. Tr. X.Y.Z); 多情只有春庭月, 独为离人照落花。(Only the sympathetic moon was shining there/For me alone on flowers fallen on the ground. Tr. X.Y.Z) In a word, the Chinese love and praise the Moon and always express their deep feelings for their hometowns or families though the Moon.

So it should be faithfully retained in its English version. In the version, the Chinese “明月” (the bright moon) is rendered into the goodness of the moon in Roman mythology, Dianna. Although such an alternative can impress foreign readers with a mythological figure, the unique flavor of an ancient Chinese poem is mixed with an oddly exotic culture. The target language readers cannot get the same artistic enjoyment as the source language readers do. After all, the Moon is still an object that Western people are very familiar with. And as the development of cultural exchange between the East and West, the "moon" image in many Chinese literary works may be translated and introduced as a cultural image to Western readers.

Original: 


\section{终日望君君不至，举头闻鹊喜。(《谒金门》冯廷已)}

Version 1:

All day long, she expects him.

But, somehow, he is not back.

She raises her head upward,

Hearing the magpie's chick-chack.

(Tr. Xu Zhongjie)

Version 2:

Waiting for you the whole day long wears out my eyes;

Raising my head, I'm glad to hear magpies.

*Magpies were supposed to announce the expected arrival.

(Tr. Xu Yuan Zhong)

This poem depicts a woman's yearning for her lover. In Chinese culture, Magpie is a symbol of happiness and singing of a magpie foretells happiness and good luck. That's why it is called 'Happy Magpie' (喜鹊) by Chinese people. It is by hearing the magpie's chattering that the woman thinks her lover is coming to her soon. However, the same bird has totally different connotation in English culture. When talking about this difference, Chen Hongwei pointed out that in English mental culture more attention is paid to the physiological characteristics of this black-and-white bird, that is noises it makes. Then the connotative meaning of a magpie in English is a chatterbox(Guo Jianzhong,1998). Therefore, in English culture, seeing a magpie means that there is a gossip in the air. A dead magpie is a bad omen saying that a careless talk can ruin your love relationship or marriage. So in the translation, it is important to avoid the culture conflicts of this bird and avoid misunderstanding. The word "magpie" is kept in both versions, but the different cultural effects are achieved since different ways are employed to keep it. In Version 1, the translator depicts it as the magpie's chick-chack. It requires the reader to figure out what magpie means in this poem. The readers might deduce from their own cultural context that the woman is so annoyed by the chattering of magpie after such a long time of waiting. But if a footnote is added, such misinterpretation can be avoided. Version2 preserves the cultural image with the word "glad", which seems to have no relevance to magpie in the western culture. Feeling the readers may wonder why the woman is happy about the magpie's crying, the translator adds a footnote to enlarge the reader's encyclopedic entry. In this way, the association between "glad" mood and "magpie" is constructed and misinterpretation is avoided, thus cultural transfer is achieved.

Original:

参差荇菜, 左右采之。

窈宓淑女, 琴瑟友之。(《诗经·关睢》)

Version 1:

The modest, retiring, virtuous, young lady:

With lutes, small and large, let us give her friendly welcome .

(Tr.James Legge)

Version 2:

O lute, play music bright

For the bride fair and slender!

(Tr. X.Y.Z)

Version 3.

Short and long the floating water plants.

Left and right you may collect them.

Gentle and graceful is the girl,

He'd like to wed her, the Qin and Se playing.

Note: Qin and Se: Two traditional Chinese musical instruments, rather like the zither; the former has seven strings and the latter twenty-five strings.(Tr. The Yangs)

In Version 1 and 2, "Qin" and "Se" are substituted by "lute", which will inevitably lead to the losses of cultural content. In Version 2, the translator adopts transliteration plus footnote, it conveys the most possible intellectual cultural content to Western readers and familiarize them with the music and musical instrument of ancient China. If the translator attempts to explain the Qin and Se within the lines, the translation will unavoidably become awkward, for it will affect the flow of rhyme and rhythm in the English version. Though the continuity of reading as pleasure has been affected by heavy annotations, the value of footnotes can be realized in assisting the target language readers in becoming acquainted with the vast cultural treasures of world literature. We hold that it is not justifiable to determine that detailed explanations like footnotes will detract from the pleasure the target language readers feel. On the contrary, it can enrich the target text reader's vision about the Chinese literature, deepen his understanding of the poem and gain aesthetic delight on a deeper level.

\section{CONCLUSION}


Just as Xu Yuanchong stated in his book On Chinese Verse in English Rhyme: If you believe to translate is to find the exact equivalence or hundred percent resemblances, then poetry is untranslatable. If you believe to translate is to find partial equivalence or convey the beauty of the original, then poetry is translatable to a certain degree (Xu Yuanchong, 1997) .Poetry is far more difficult to translate as compared with other forms of literary works. It poses a difficult task for the translators to translate a ancient Chinese poem with the original features retained, and to make the TL readers perceive the beauties of the original poem and the unique favor of Chinese culture at the meantime. Absolute equivalence can never be established although relative equivalents can be achieved at different levels depending on the cultural capacity, aesthetic attainment and skills of the translator (Wang Ning, 2010).

\section{REFERENCES}

[1] Gao Jiazheng. (1999). An important Strategy in the Translation of Ancient Poems into English. Shanghai Journal of Translators 9.4, 34-36.

[2] Guo Jianzhong. (1998). Culture and Translation. Beijing: China Translation Corporation.

[3] Wang Ning. (1996). Toward a translation study in the context of Chineseâ€ western comparative culture studies. Perspectives-studies in translation theory and practice, 4. 43-45.

[4] Xun Yuanchong. (1992). On Chinese Verse in English Rhyme. Beijing: Peking University Press.

[5] Zhu Guangqian. (1984). On Poetry. Shanghai: SDX Joint Publishing Company.

Hongwei Ye was born in Jiangxi, China in 1978. He received his MA degree in English language and literature from Shanghai University, China, in 2006. He is currently an associate professor in the School of Foreign languages, Shanghai University of Engineering Science, Shanghai, China. His research interests include English language teaching, translation theory and practice. He is a member of Shanghai Science and Technology Translation Society. 